IJ§ER

ISSN: $2149-5939$
International Journal of Social Sciences and Education Research

Online, http://dergipark.gov.tr/ijsser

Volume: 3(2), 2017

\title{
Beliren yetişkinlik dönemindeki bireylerde ilişkilerle ilgili bilişsel çarpıt- malar ve psikolojik iyi oluş arasındaki ilişkinin incelenmesi
}

\author{
Examination of relationship between interpersonal cognitive distortions and psycho- \\ logical wellbeing among emerging adulthood individuals
}

\author{
Aynur Karabacak ${ }^{1}$
}

\begin{abstract}
Received Date: $01 / 09$ / 2016
Accepted Date: 15 / $01 / 2017$

$\ddot{O} z$

Bu araştırmanın temel amacı beliren yetişkinlik dönemindeki üniversite ögrencilerinin iliş̧kilerle ilgili bilişsel çarpıtmaları ve psikolojik iyi oluşları arasındaki ilişkinin incelenmesidir. Araştırma 2016-2017 eğitim ögretim yılı güz yarlyılında Atatürk Üniversitesi Kazım Karabekir Ĕ̈itim Fakültesi’nde ögrenimine devam etmekte olan 253 lisans öğrencisi üzerinde gerçekleştirilmiştir. Araştırma kapsamında İlişkilerle İlgili Bilişsel Çarpıtmalar Ölçeği ve Psikolojik İyi Oluş Ölçeği kullanılmıştır. Araştırma sonucunda elde edilen veriler üzerinde bilişsel çarpıtmalar ve psikolojik iyi oluş arasındaki iliş̧i Pearson Momentler Çarpımı korelasyon analizi ile, bilişsel çarpıtmaların psikolojik iyi oluş üzerindeki yordayıcı etkisi ise hiyerarşik çoklu regresyon analizi ile incelenmiştir. Araştırma sonucunda ilişkilerle ilgili bilişsel çarpıtmalar ölçeğinin yakınlıktan kaçınma alt boyutu ile psikolojik iyi oluş arasında negatif yönlü, zihin okuma alt boyutu ile pozitif yönlü anlamlı bir ilişki olduğu saptanmıştır. Bununla birlikte yakınlıktan kaçınma ve zihin okumanın psikolojik iyi oluşun anlamlı yordayıcıları olduğu görülmüşı̈rr.
\end{abstract}

Anahtar sözcükler: Beliren yetişkinlik dönemi, bilişsel çarpıtmalar, psikolojik iyi oluş.

\begin{abstract}
The main purpose of this research is to examine the relationship between cognitive distortions and psychological wellbeing in emerging adulthood university students. The research was carried on 253 university students who continue their education in Ataturk University Kazım Karabekir Education Faculty in 2016-2017 education years. Interpersonal Cognitive Distortions Scale and Psychological Well Being Scale were used in the research. On the data obtained in the survey the relationship between cognitive distortions and psychological wellbeing is examined with Pearson correlation analysis, and the predictive effect of cognitive distortions in psychological wellbeing is examined with hierarchical multiple regression analysis. Research results indicate that there is a negative significant relationship between cognitive distortions avoidance of intimacy sub scale and psychological wellbeing and a positive significant relationship between mind reading and psychological wellbeing. Besides avoidance of intimacy and mind reading are significant predictors of psychological wellbeing.
\end{abstract}

Keywords: Emerging adulthood, cognitive distortions, psychological wellbeing

\section{Giriş}

Bilişsel yaklaşımlar tarafından ortaya atılan bilişsel çarpıtmalar kavramı, bireyin kendini ve çevresini işlevsel olmayan şemalarına uydurabilmek için çarpık olarak algılaması durumudur. Kişi aldığı yeni bir bilgiyi bilişsel düzeyde işlerken var olan zihinsel yapılarına uygun hâle getirebilmek için sıklıkla çarpıtmakta ve bu çarpıtılmış değerlendirmeler de otomatik düşünceler olarak bilinç düzeyine çıkmaktadırlar (Beck, 2001; Turan, 2010). Bilişsel çarpıtmaların, bireyin içinde bulunduğu ortamı değerlendirme ve bu değerlendirmeyi yorumlama biçimini işlevsiz kılan

1 Atatürk Üniversitesi Kazım Karabekir Eğitim Fakültesi Eğitim Bilimleri Bölümü Rehberlik ve Psikolojik Danışmanlık Anabilim Dalı, Erzurum, TÜRKIYE, aynur.karabacak@atauni.edu.tr 
Karabacak, A. (2017). Beliren yetişkinlik dönemindeki bireylerde ilişkilerle ilgili bilişsel çarpıtmalar ve psikolojik iyi oluş arasındaki ilişkinin incelenmesi. International Journal of Social Sciences and Education Research, 3(2), 425-433.

ve uyumu bozan bir yönü olduğu bilinmektedir. Bilişsel çarpıtmaları kullanan birey, bilgileri hatalı işlediği için duygusal sorunlar ortaya çıkabilmektedir (Beck, 2001; Corey, 1996; Türkçapar, 2012). Bu bağlamda düşünce düzeyinde meydana gelen hatalı inançların bireyin duygusal açıdan sorun yaşamasına neden olacağı söylenebilir.

Sosyal ortam içerisinde hayatını devam ettiren insanoğlunun diğer insanlarla kurduğu ilişkilere dair sahip olduğu akılcı olmayan ve çarpıtılmış düşüncelerin kişinin davranış şekillerini de etkilediği bilinmektedir. Bireylerde hem duygusal sorunları meydana getiren hem de davranışsal sorunlara yol açan bu düşünceler ilişkilerle ilgili bilişsel çarpıtmalar olarak adlandırılmaktadır (DiGiuseppe ve Zee, 1986; Akt. Uğur ve Murat, 2014). İlişkilerle ilgili bilişsel çarpıtmaları olan birey sosyal ilişkilerinde karşı tarafın söylediklerini yanlış yorumlamakta (Akın, 2010) ve bireyler arası kurduğu ilişkilerde çatışma yaşamaya daha yatkın hâle gelmektedir (Hamamcı ve Büyüköztürk, 2003). Yapılan araştırmalar bilişsel çarpıtmaları yoğunlukla kullanan birerlerde saldırganlık (Baldık, 2005; Fives, Kong, Fuller ve DiGiuseppe, 2011; Uğur ve Murat, 2014) ve zorbalık (Şahin ve Sarı, 2010) eğiliminin de yüksek olduğunu ortaya koymuştur. Bu bağlamda ele alındığına bilişsel çarpıtmaların bireylerin kişiler arası ilişkilerinde sorun yaşamasına neden olacağı ve genel anlamda bireyde olumsuz duyguları ortaya çıkaracağ düşünülebilir. İlişkilerle ilgili sahip olunan bilişsel çarpıtmaların bireyde olumsuz duyguları açığa çıkarması sonucunda kişinin olumlu duyguları daha az yaşayacağı söylenebilir.

Ruh sağlığına dair yapılan çalışmalarda genellikle depresyon ve anksiyete gibi olumsuz kavramlar üzerinde durulduğu görülmektedir. Bununla birlikte olumlu kavramları inceleme eğiliminin de arttığı söylenebilir (Telef, 2013). Ruh sağlığı ile ilgili olumlu kavramlardan birinin 1980’li yıllardan itibaren kullanılmaya başlanan psikolojik iyi oluş kavramı olduğu bilinmektedir. Psikolojik iyi oluş, zorluklarla karşı karşıya kalındığında ortaya çıkan anlamlı amaçlar sürdürme, kişisel gelişim, başkaları ile nitelikli ilişkiler kurabilme gibi varoluşsal süreçleri yönetme olarak tanımlanmaktadır (Keyes, Shmotkin ve Ryff, 2002). Bu kavram olumlu olarak işlev gösteren bireyin özelliklerini içermektedir (Özen, 2010). Bununla birlikte psikolojik iyi oluşun bilişsel, duyuşsal, fiziksel, kişisel süreçlerle ilişkisinin olabileceği de araştırmalar sonucu ortaya konmuştur (Roothman, Kirsten ve Wissing, 2003). Bu açıdan değerlendirildiğinde kişilerarası ilişkilerde ortaya çıkan bilişsel çarpıtmaların da bilişsel, duyuşsal ve davranışsal öğelerinin olduğu düşünüldüğünde bireylerin düşünce düzeyinde ortaya koydukları ilişkilerine dair bilişsel çarpıtmalarının onların psikolojik iyi oluşlarına olumsuz olarak etki edeceği söylenebilir.

Beliren yetişkinlik döneminde yer alan üniversite öğrencilerinden akademik ve sosyal hayata uyum gösterme, olumlu bir kimlik oluşumunu devam ettirme ve yakın ilişkiler kurma noktasında çeşitli gelişim görevlerini başarmaları beklenmektedir (Küçükarslan ve Gizir, 2014). Bu gelişim görevleri başarılmaya çalışılırken bireyler kişiler arası ilişkilerde işlevsel olmayan inançlar geliştirebilmekte (Hamamc1, 2002), bu durum da bireyde olumsuz duyguları ortaya çıkarabilmekte (Uğur ve Murat, 2014) ve sonuç olarak psikolojik iyi oluşa olumsuz etki edeceği düşünülmektedir. Bu nedenle beliren yetişkinlik dönemindeki bireylerde ilişkilerle ilgili bilişsel çarpıtmalar ve psikolojik iyi oluş arasındaki ilişkilerin ortaya konması, bu dönemde bireylerin ruh sağlığına etki eden değişkenlerin belirlenmesine ve ortaya çıkan olumsuzlukların önlenmesine yardım edeceğinden dolayı önemli olarak görülmektedir. Bu bağlamda bu araştırmada aşağıda belirtilen sorulara cevap aranmıştır: 
Karabacak, A. (2017). Examination of relationship between interpersonal cognitive distortions and psychological wellbeing among emerging adulthood individuals. International Journal of Social Sciences and Education Research, 3(2), 425-433.

Beliren yetişkinlik dönemindeki bireylerde ilişkilerle ilgili bilişsel çarpıtmalarla psikolojik iyi oluş arasında anlamlı bir ilişki var mıdır?

Beliren yetişkinlik dönemindeki bireylerde ilişkilerle ilgili bilişsel çarpıtmalar psikolojik iyi oluşun anlamlı bir yordayıcısı mıdır?

\section{Yöntem}

\subsection{Araştırma modeli}

$\mathrm{Bu}$ araştırma tarama modeline uygun olarak gerçekleştirilmiştir. Tarama modelinde değişkenler arasında bir ilişkinin olup olmadığı ve bu ilişkinin düzeyi ele alınmaya çalışılmaktadır (Christensen, Johnson ve Turner, 2015).

\subsection{Evren-örneklem}

$\mathrm{Bu}$ araştırmanın evrenini 2016-2017 öğretim yılında Atatürk Üniversitesi Kazım Karabekir Eğitim Fakültesine devam eden lisans düzeyindeki öğrenciler oluşturmaktadır. Araştırmanın örneklemini ise evrenden uygun örnekleme yöntemi ile seçilen 253 lisans düzeyindeki öğrenci oluşturmaktadır. Araştırmaya katılan öğrencilerin \% 70.4'ü kız, \% 29.6'sı erkektir. Öğrencilerin \% 65.2'si 1. sınıf, \% 16.2'si 2. sınıf, \% 8.3'ü 3. sınıf ve \% 10.3'ü 4. sinıfta öğrenimine devam etmektedir. Öğrencilerin yaş ortalaması 19.2`dir. Araştırmaya Türkçe, Matematik, Fen Bilgisi, Coğrafya Öğretmenliği ve Rehberlik ve Psikolojik Danışmanlık anabilim dallarında öğrenimine devam eden öğrenciler katılmıştır.

\subsection{Veri toplama araçları}

Kişisel bilgi formu; Araştırma kapsamında bireylerin cinsiyet, sınıf, yaş, bölüm özelliklerine ait bilgi toplamak amacıyla araştırmacı tarafından hazırlanan formdur.

Illişkilerle ilgili bilişsel çarpıtmalar ölçeği; Hamamcı (2002) tarafından geliştirilen ölçek, bireylerin kişiler arası ilişkilerinde sahip oldukları bilişsel çarpıtmaları belirlemektedir. Ölçek 19 maddeden ve 5'li likert tipinden oluşmakta ve ölçekten en düşük 19, en yüksek 95 puan alınabilmektedir. Ölçeğin maddeleri "hiç katılmıyorum"dan "tamamen katılıyorum"a kadar derecelendirilmektedir. Ölçekten alınan puanların yüksek olması bireylerin işiler arası ilişkileri ile ilgili bilişsel çarpıtmalarının olduğunu ortaya koymaktadır (Hamamcı, 2002; Hamamcı ve Büyüköztürk, 2003).

Ölçeğin temel bileşenler analizi yöntemiyle incelenen faktör yapısına göre yakınlıktan kaçınma, gerçekçi olmayan ilişki beklentisi ve zihin okuma olmak üzere üç alt boyutu bulunmaktadır. Ölçeğin ölçüt geçerliğini belirlemek için Bilişsel Çarpıtmalar Ölçeği, Otomatik Düşünceler Ölçeği ve Çatışma Eğilim Ölçeği ile korelasyon değerlerinin pozitif yönlü ve anlamlı olduğu bulunmuştur $(\mathrm{p}<.01)$. Ölçeğin iç tutarlılığına bakıldığında bu değerlerin ölçeğin tamamı için .67, Yakınlıktan Kaçınma için .73, Gerçekçi Olmayan İlişki Beklentisi için .66 ve Zihin Okuma için .49 olduğu görülmüştür. Test tekrar test güvenirliğine bakıldığında ise bu değerin ölçeğin tamamı için .74, Yakınlıktan Kaçınma için .74, Gerçekçi Olmayan İlişki Beklentisi için .76 ve Zihin Okuma için .74 olduğu saptanmıştır (Hamamcı ve Büyüköztürk, 2003).

$\mathrm{Bu}$ araştırma kapsamında ölçeğin güvenirliği ölçeğin tümü için .75, Yakınlıktan Kaçınma için .66, Gerçekçi Olmayan İlişki Beklentisi için .69 ve Zihin Okuma için . 63 olarak bulunmuştur. 
Karabacak, A. (2017). Beliren yetişkinlik dönemindeki bireylerde ilişkilerle ilgili bilişsel çarpıtmalar ve psikolojik iyi oluş arasındaki ilişkinin incelenmesi. International Journal of Social Sciences and Education Research, 3(2), 425-433.

Psikolojik iyi oluş ölçeği; Diener ve arkadaşları (2009-2010) tarafından geliştirilen ve Telef (2013) tarafından Türkçeye uyarlanmış olan ölçek bireylerin psikolojik iyi oluşlarını ölçmeyi amaçlamaktadır. Ölçek 8 maddeden oluşmakta ve 7'li likert tipinde olup maddeler "hiç katılmıyorum"dan "tamamen katılıyorum"a kadar derecelendirilmektedir. Ölçek tek boyuttan oluşmakta ve ölçekten en düşük 8, en yüksek 56 puan alınmaktadır. Alınan puanların yüksek olması bireyin pek çok kaynağı kullanmakta başarılı olduğu ve genel olarak psikolojik iyi oluşunun yüksek olduğu anlamına gelmektedir. Açımlayıcı faktör analizi sonucuna göre açıklanan toplam varyansın \%42 olduğu bulunmuştur. Doğrulayıcı faktör analizi sonuçlarına göre elde edilen uyum indeksleri RMSEA $=0.08, \mathrm{SRMR}=0.04, \mathrm{GFI}=0.96, \mathrm{NFI}=0.94, \mathrm{RFI}=0.92, \mathrm{CFI}=0.95$ ve $\mathrm{IFI}=0.9$ olarak saptanmıştır. Test tekrar test güvenirliğine göre iki uygulama arasında pozitif ve anlamlı bir ilişki olduğu görülmüsstür $(r=0.86, p<.001)$. Ölçeğin güvenirliğine bakıldığında Cronbach alfa değeri .80 olarak bulunmuştur.

$\mathrm{Bu}$ araştırma kapsamında ölçeğin güvenirliği .80 olarak hesaplanmıştır.

\section{Bulgular}

\section{1. İlişkilerle ilgili bilişsel çarpıtmalar ve psikolojik iyi oluş arasındaki ilişkiye dair bulgular}

İlişkilerle ilgili bilişsel çarpıtmalar ve psikolojik arasında anlamlı bir ilişki olup olmadığını belirlemek amacıyla Pearson Momentler Çarpımı Korelasyon analizi uygulanmış ve sonuçlar Tablo 1'de verilmiştir.

Tablo 1. İlişkilerle ilgili bilişsel çarpıtmalar ve psikolojik iyi oluş arasındaki ilişkiler

\begin{tabular}{|c|c|c|c|c|c|}
\hline & & 1 & 2 & 3 & 4 \\
\hline \multirow{2}{*}{ 1. Psikolojik İyi Oluş } & $r$ & & & & \\
\hline & $\mathrm{p}$ & & & & \\
\hline \multirow{2}{*}{ 2. Yakınlıktan Kaçınma } & $\mathrm{r}$ & $-.33^{* *}$ & & & \\
\hline & $\mathrm{p}$ & .000 & & & \\
\hline \multirow{2}{*}{$\begin{array}{l}\text { 3. Gerçekçi Olmayan İlişki Bek- } \\
\text { lentisi }\end{array}$} & $\mathrm{r}$ & .05 & $.26^{* *}$ & & \\
\hline & $\mathrm{p}$ & .478 & .000 & & \\
\hline \multirow{2}{*}{ 4. Zihin Okuma } & $\mathrm{r}$ & $.22^{* *}$ & $.22^{* *}$ & $.31^{* *}$ & \\
\hline & $\mathrm{p}$ & .000 & .000 & .000 & \\
\hline \multicolumn{2}{|l|}{$\overline{\bar{X}}$} & 41.21 & 19.92 & 24.04 & 9.81 \\
\hline \multicolumn{2}{|l|}{ S.S. } & 8.17 & 5.36 & 5.58 & 2.64 \\
\hline
\end{tabular}

Tablo 1. incelendiğinde psikolojik iyi oluş ile ilişkilerle ilgili bilişsel çarpıtmalar ölçeğinin yakınlıktan kaçınma alt boyutu arasında negatif yönlü $(\mathrm{r}=-.33, \mathrm{p}<.001)$, zihin okuma $(\mathrm{r}=.22$, $\mathrm{p}<.001$ ) alt boyutu arasında pozitif yönlü anlamlı bir ilişki olduğu görülmektedir. Ancak ilişkilerle ilgili bilişsel çarpıtmalar ölçeğinin gerçekçi olmayan ilişki beklentisi $(r=.05, \mathrm{p}>.05)$ alt boyutu ile psikolojik iyi oluş arasında anlamlı bir ilişki olmadığı saptanmıştır. 
Karabacak, A. (2017). Examination of relationship between interpersonal cognitive distortions and psychological wellbeing among emerging adulthood individuals. International Journal of Social Sciences and Education Research, 3(2), 425-433.

\subsection{Psikolojik iyi oluşun yordanmasına ilişkin bulgular}

Psikolojik iyi oluşun anlamlı yordayıcılarının belirlenmesi amacıyla hiyerarşik regresyon analizi uygulanmış olup sonuçlar Tablo 2'de verilmiştir.

Tablo 2. Psikolojik iyi oluşun yordanması

\begin{tabular}{lccccc}
\hline & $\mathrm{B}$ & $\mathrm{SH}_{\mathrm{B}}$ & $\beta$ & $\mathrm{t}$ & $\mathrm{p}$ \\
\hline Blok/Sıra & & 1.87 & - & 27.39 & .000 \\
\hline 1. Sabit & 51.26 & .09 & -.33 & -5.56 & .000 \\
\hline Yakınlıktan Kaçınma & -.51 & 2.25 & - & 19.58 & .000 \\
2. Sabit & 43.98 & .09 & -.40 & -6.88 & .000 \\
$\quad$ Yakınlıktan Kaçınma & -.61 & .18 & .31 & 5.30 & .000 \\
\hline
\end{tabular}

Tablo 2. incelendiğinde analizin iki aşamada tamamlandığı görülmektedir. Analize birinci aşamada psikolojik iyi oluş değişkeninde \% 11 ile en fazla varyansı açıklayan yakınlıktan kaçınma değişkeni girmiştir. Yakınlıktan kaçınma puanı arttıkça psikolojik iyi oluş puanı azalmaktadır $(\mathrm{t}=$ $-5.56, \mathrm{p}<.001)$. Analize ikinci aşamada varyansa \% 9 katkı sağlayan zihin okuma dâhil olmuş ve böylece açıklanan varyans \%20'ye yükselmiştir. Zihin okuma puanı arttıkça psikolojik iyi oluş puanı da artmaktadır $(\mathrm{t}=5.30, \mathrm{p}<.001)$.

Tablo 3. İlişkilerle ilgili bilişsel çarpıtmalar ölçeğinin alt boyutlarının toplam varyansı açıklama oranları ve varyansa katkıları

\begin{tabular}{lcccc}
\hline Blok/Sıra & $\mathrm{F}_{\mathrm{REG} .}$ & $\mathrm{F}_{\text {değișim }}$ & $\mathrm{R}_{\text {değişim }}$ & $\mathrm{R}^{2}$ \\
\hline 1. Yakınlıktan & $30.92^{*}$ & $30.92^{*}$ & $.11^{*}$ & .11 \\
Kaçınma & $31.19^{*}$ & $28.11^{*}$ & $.09^{*}$ & .20 \\
2. Zihin Okuma & & & &
\end{tabular}

Tablo 3. incelendiğinde yapılan hiyerarşik regresyon analizi sonucunda analize ilk sırada dâhil edilen yakınlıktan kaçınma değişkeni psikolojik iyi oluşa ilişkin varyansın \%11'ini açılamıştır. Yakınlıktan kaçınmanın varyansa katkısı anlamlıdır $\left(\mathrm{F}_{\text {reg }}(1 ; 251)=30.92, \mathrm{p}<.001\right)$. Hiyerarşik çoklu regresyon analizine ikinci aşamada giren zihin okuma alt boyutu yakınlıktan kaçınma ile birlikte toplam varyansın \% 20'sini açıklamaktadır ve her bir bloğun varyansı yordama gücü anlamlıdır $\left(\mathrm{F}_{\text {reg }}(2 ; 250)=31.19, \mathrm{p}<.001\right)$. Zihin okuma psikolojik iyi oluşa ait birinci aşamada açıklanan varyansa \% 9'luk bir katkıda bulunmuştur ve iki alt boyutun da $\mathrm{R}^{2}$, de sağladığı artış anlamlidır $\left(\mathrm{F}_{\text {değişim }}(1 ; 251)=28.11, \mathrm{p}<.001\right)$.

\section{Sonuç ve öneriler}

$\mathrm{Bu}$ bölümde beliren yetişkinlik dönemindeki bireylerde ilişkilerle ilgili bilişsel çarpıtmalar ve psikolojik iyi oluş arasındaki ilişkilerin belirlenmesinin amaçlandığı bu araştırma sonucunda elde edilen bulgular literatür doğrultusunda yorumlanmıştır.

İlişkilerle ilgili bilişsel çarpıtmalar ölçeğinin yakınlıktan kaçınma alt boyutu ile psikolojik iyi oluş arasında negatif yönlü, zihin okuma alt boyutu ile psikolojik iyi oluş arasında pozitif yönlü anlamlı bir ilişkiler olduğu görülmüsstür. Araştırma sonucunda elde edilen bu bulguyu literatürde 
Karabacak, A. (2017). Beliren yetişkinlik dönemindeki bireylerde ilişkilerle ilgili bilişsel çarpıtmalar ve psikolojik iyi oluş arasındaki ilişkinin incelenmesi. International Journal of Social Sciences and Education Research, 3(2), 425-433.

destekleyen araştırmalar olduğu görülmektedir. Çelik ve Odacı (2013) tarafından yapılan çalışmada ilişkilerle ilgili bilişsel çarpıtmalar ile yaşam doyumu arasında negatif bir ilişki olduğunu ortaya koymuşlardır. Tümkaya, Çelik ve Aybek (2011) tarafından yapılan çalışmada da otomatik düşünceler ile yaşam doyumu arasında negatif yönlü anlamlı ilişkiler olduğu bulunmuştur. Day ve Maltby (2003) olumlu düşünce ile depresyon, kaygı ve akılcı olmayan inançlar arasında negatif yönde anlamlı ilişkiler olduğunu ortaya koymuşlardır. Bu bağlamda ele alındığında, bireylerin yakınlık kurmaktan kaçınmaya dönük geliştirdikleri işlevsel olmayan ilişki inançlarının kendilerini sosyal ortamlardan uzak tutmalarına neden olacağı ve bireylerde yalnızlık duygusunu ortaya çıkarıp psikolojik iyi oluşlarını olumsuz olarak etkileyeceği şeklinde yorumlanabilir. Bununla birlikte araştırma sonucunda beklenmedik şekilde zihin okuma alt boyutu ile psikolojik iyi oluş arasında pozitif yönlü ilişkiler olduğu görülmüştür. Araştırma sonucunda elde edilen bu bulguyu literatürde doğrudan destekleyen bir çalışma olmamakla birlikte; elde edilen bu bulgu bireylerin sosyal ilişki kurduğu bireyler tarafından zihinlerinden geçenleri söylemese dahi anlaşılacağına dair geliştirdiği inançların iyi oluşlarını olumlu olarak etkilediği şeklinde yorumlanabilir. İnsanlar sosyal iletişim içinde olduğu kişiler tarafından anlaşılmayı, kabul görmeyi, onaylanmayı beklemektedirler. Her ne kadar zihin okuma ilişkilere dair bir bilişsel çarpıtma türü olsa da (Hamamcı, 2002) bireyler iletişim kurdukları kişiye düşüncelerini açmasalar dahi onlar tarafından anlaşılmayı beklemeleri ve bu durumun sosyal ilişkilerde pekiştirilmesi sonucunda kişilerin psikolojik iyi oluşları bu durum neticesinde artıyor olabilir. Bir başka ifade ile bireyler zihinleri okunurcasına aklından geçenleri karşı tarafın bilmesini iletişim kurdukları kişi ile aralarında oluşan bir bağ olarak da nitelendiriyor olabilir.

Araştırma soncunda elde edilen ikinci bulguya göre yakınlıktan kaçınma ve zihin okumanın psikolojik iyi oluşun anlamlı yordayıcıları olduğu saptanmıştır. Bireylerin yakınlık kurmaktan kaçınmaları gerektiğine dair düşünceleri psikolojik iyi oluşlarını olumsuz olarak etkilemektedir. Sosyal ilişkilerden kendini soyutlaması gerektiğini düşünen birey bu düşünce yüzünden kendini daha yalnız hissetmekte ve sonuç olarak kişinin psikolojik iyi oluşu bundan olumsuz olarak etkileyebilmektedir. Bununla birlikte zihin okumanın psikolojik iyi oluşu anlamlı düzeyde yordadığı bulgusu bireylerin sosyal ilişki kurulan kişi tarafından anlaşılma isteği ile açıklanabilir. Birey herhangi bir çaba göstermese bile ilişkide olduğu bireyin kendi zihninden geçenleri okuyormuşçasına bilmesi kişide daha iyi anlaşıldığ duygusunu oluşturabilir. Bu durum da bireyde iyi oluşu artıran bir durum olarak ele alınabilir.

Beliren yetişkinlik döneminde yer alan bireylerde psikolojik iyi oluşu etkileyen faktörlerin incelendiği bu çalışma sonuçlarına göre, psikolojik danışmanlara iyi oluşu artırmaya dönük grupla psikolojik danışma veya grup psikoeğitim programları düzenlemeleri önerilebilir. Bireyle ya da grupla psikolojik danışma sürecinde bireylerin ilişkilere dair geliştirdikleri bilişsel çarpıtmalar üzerinde durulabilir.

\section{Kaynakça}

Akın, A. (2010). Öz duyarlık ve ilişkilerle ilgili bilişsel çarpıtmalar. Hacettepe Üniversitesi Eğitim Fakültesi Dergisi, 39, 01-09.

Baldık, Ö. (2005). Ansiklopedik Eğitim ve Psikoloji Rehberi. İstanbul: Timaş Yayınları.

Beck, J. (2001). Bilişsel Terapi: Temel İlkeler ve Ötesi. (Çev. N. Hisli Şahin) Ankara: Türk Psikologlar Derneği. 
Karabacak, A. (2017). Examination of relationship between interpersonal cognitive distortions and psychological wellbeing among emerging adulthood individuals. International Journal of Social Sciences and Education Research, 3(2), 425-433.

Christensen, L. B., Johnson, R. B., \& Turner, L. A. (2015). Araştırma Yöntemleri: Desen ve Analiz (Çev. A. Alpay). Ankara: Anı Yayıncılık.

Corey, G. (1996). Theory and Practice of Counselling and Psychotherapy. California: Broks/Cole.

Çelik, Ç. B., \& Odacı, H. (2013). The relationship between problematic internet use and interpersonal cognitive distortions and life satisfaction in university students. Children and Youth Services Review, 35(3), 505-508.

Day, L., \& Maltby, J. (2003). Belief in good luck and psychological wellbeing: The mediating role of optimism and irrational beliefs. Journal of Psychology, 137, 99-110.

Diener, E. D., Emmons, R. A., Larsen, R. J., \& Griffin, S. (1985). The satisfaction with life scale. Journal of Personality Assessment, 49(1), 71-75.

DiGiuseppe, R., \& Zee, C. (1986). A rational emotive theory of marital dysfunctional marital therapy. Journal of Rational Emotive Therapy, 4, 22-37.

Fives, C. J., Kong, G., Fuller, J. R., \& DiGiuseppe, R. (2011). Anger, aggression, and irrational beliefs in adolescents. Cognitive Therapy and Research, 35(3), 199-208.

Hamamc1, Z. (2002). Bilişsel davranışçı yaklaşımla bütünleştirilmiş psikodrama uygulamasının kişilerarası ilişkilerle ilgili bilişsel çarpıtmalar ve temel inançlar üzerine etkisi. Yayımlanmamış Doktora Tezi Ankara Üniversitesi, Sosyal Bilimler Enstitüsü, Ankara.

Hamamcı, Z. (2002). Ergenlerin yalnızlık düzeyleri ve kişilerarası ilişkilerle ilgili bilişsel çarpıtmaları arasındaki ilişkinin incelenmesi. Yayımlanmamış Yüksek Lisans Tezi, Ankara Üniversitesi, Sosyal Bilimler Enstitüsü, Ankara.

Hamamc1, Z., \& Büyüköztürk, Ş. (2003). İlişkilerle ilgili bilişsel çarpıtmalar ölçeği, ölçeğin geliştirilmesi ve psikometrik özelliklerinin incelenmesi. Çukurova Üniversitesi Ĕ̆itim Fakültesi Dergisi, 2(25), $107-$ 111.

Keyes, C. L. M., Shmotkin, D., \& Ryff, C. D. (2002) Optimizing well-being: The empirical encounter of two traditions. Journal of Personality and Social Psychology, 82, 1007-1022.

Küçükarslan, M., \& Gizir, C. A. (2014). Üniversite öğrencilerinin romantik ilişki inançlarinin çeşitli değişkenler açısından incelenmesi. Türk Psikolojik Danışma ve Rehberlik Dergisi, 5(42), 148-159.

Özen, Y. (2010). Kişisel sorumluluk bağlamında öznel ve psikolojik iyi oluş (sosyal psikolojik bir değerlendirme). Dicle Üniversitesi Sosyal Bilimler Enstitüsü Elektronik Dergisi, 4, 46-58.

Roothman, B., Kirsten, D. K., \& Wissing, M. P. (2003). Gender differences in aspects of psychological well-being. South African Journal of Psychology, 33, 212-218.

Şahin, M., \& Sarı, S. V. (2010). Ergenlerde görülen zorbalık eğiliminin bilişsel çarpıtmalar ve fonksiyonel olmayan tutumlarla ilişkisi. Akademik Bakış Dergisi, 20(9), 1-14.

Telef, B. B. (2013). Psikolojik iyi oluş ölçeği (PİOO): Türkçeye uyarlama, geçerlik ve güvenirlik çalışması. Hacettepe Ĕ̈itim Fakültesi Dergisi, 28(3), 374-384.

Turan, A. F. (2010). Üniversite ögrrencilerinin ilişkilerle ilgili bilişsel çarpıtmalarını yordamada yalnızlık, benlik saygısı, yaş, cinsiyet ve romantik ilişki yaşama durumunun rolü. Yayımlanmamış yüksek lisans tezi. Anadolu Üniversitesi, Eğitim Bilimleri Enstitüsü, Eskişehir.

Tümkaya, S., Çelik, M., \& Aybek, B. (2011). Lise öğrencilerinde boyun eğici davranışlar otomatik düşünceler umutsuzluk ve yaşam doyumunun incelenmesi. Çukurova Üniversitesi Sosyal Bilimler Enstitüsü Dergisi, 20(2), 77-94. 
Karabacak, A. (2017). Beliren yetişkinlik dönemindeki bireylerde ilişkilerle ilgili bilişsel çarpıtmalar ve psikolojik iyi oluş arasındaki ilişkinin incelenmesi. International Journal of Social Sciences and Education Research, 3(2), 425-433.

Türkçapar, M. H. (2000). Kognitif terapi ve psikanalize bakışı. 3P Dergisi, 8, 1-44.

Uğur, E., \& Murat, M. (2014). Lise öğrencilerinin kişilerarası ilişkilerle ilgili bilişsel çarpıtmaları ve saldırganlık tepkileri arasındaki ilişkinin incelenmesi. University of Gaziantep Journal of Social Sciences, 13(2), 525-543.

\section{Extended abstract in English}

The concept of cognitive distortions is a perceived cognition of the individual in order to adapt to his non-functional schemas. Individuals frequently distort a new knowledge they receive in order to be able to adapt to the existing mental structures of the cognitive level (Beck, 2001; Turan, 2010). It is known that cognitive distortions are a way of evaluating the environment in which the individual is in and interpreting it, which is dysfunctional and distorts harmony. Individuals who use cognitive distortions cause emotional problems because they process the information wrongly (Beck, 2001, Corey, 1996). In this context, it can be said that distorted beliefs that occur at the level of thought may be cause emotional problems. As emotional problems increase psychological well-being may be decrase.

Psychological well-being is defined as the management of existential processes such as sustaining meaningful goals, personal development, and establishing quality relationships with others when confronted with difficulties (Keyes, Shmotkin and Ryff, 2002). This concept includes the features of the positively functioning individual (Özen, 2010). However, research has also revealed that psychological well-being may be related to cognitive, emotional, physical, and personal processes (Roothman, Kirsten and Wissing, 2003). From this point of view, it can be said that the cognitive distortions will negatively affect their psychological well-being.

It is expected that university students those who are in emerging adulthood will be able to fulfill various development tasks at the point of adapting to academic and social life, maintaining a positive identity formation and establishing close relationships (Küçükarslan and Gizir, 2014). While trying to achieve these developmental tasks, individuals may develop nonfunctional beliefs among interpersonal relationships (Hamamc1, 2002), which may lead to negative emotions in the individual (Uğur and Murat, 2014), and as a result it is thought to have a negative impact on psychological well-being. In this context, in this research it is examined whether there is a relationship between interpersonal cognitive distortions and psychological well being or not.

This research was conducted in accordance with the screening model. In the screening model, the relationship between the variables and the level of this relationship is tried to be addressed (Christensen, Johnson and Turner, 2015). The universe of this research is the undergraduate students who are studying at Atatürk University Kazım Karabekir Education Faculty in 2016-2017 academic year. The sample of the research is composed of 253 undergraduate students who are selected by appropriate sampling method. Personal Information Form, Interpersonal Cognitive Distortions Scale and Psychological Well Being Scale were used.

Research results indicate that there was a negative significant relationship between avoidance of intimacy sub dimension of interpersonal cognitive distortions scale and psychological wellbeing, and a positive relationship between mind reading subscale and psychological well-being. This finding is supported by the results of the research (Çelik and Aybek, 2011; Çelik and Odac1, 2013; Day and Maltby, 2003). When considered in this context, it can be interpreted that the nonfunctional relationship beliefs will cause individuals to keep themselves away from the 
Karabacak, A. (2017). Examination of relationship between interpersonal cognitive distortions and psychological wellbeing among emerging adulthood individuals. International Journal of Social Sciences and Education Research, 3(2), 425-433.

social environment, and will manifest the feeling of loneliness in individuals and negatively affect their psychological well-being. Nevertheless it has been unexpectedly found that there wass a positive significant relationship between mind reading sub-dimension and psychological wellbeing Although this finding is not directly supported in the literature, it can be interpreted that this finding positively influences the well-being of the individuals because people are expected to be understood, accepted and approved by those who are in social communication. Although it is a type of cognitive distortions related to mind-reading associations (Hamamc1, 2002), even if the individuals open their minds to the person they communicate with, they should expect to be understood by them, and as a result of this consolidation in social relations, the psychological well-being of the individuals may be increasing.

According to the second finding, avoidance of intimacy and mind reading were found to be significant predictors of psychological well-being. Individuals who think that he / she needs to isolate himself/herself from social relations feels lonely because of this thought and as a result the psychological well-being of the person is adversely affected. However, the fact that reading the mind can reasonably predict psychological well-being can be explained by the desire of individuals to be understood by the social relations person. According to the research results, it can be suggested to the psychological counselors to organize psychological counseling or group psychoeducation programs to increase psychological well-being. Besides in psychological counseling, cognitive distortions can be emphasized. 